\title{
Metatarsal Bone Digit 1
}

National Cancer Institute

\section{Source}

National Cancer Institute. Metatarsal Bone Digit 1. NCI Thesaurus. Code C52791.

The first and most medial of the five long bones located in the mid-foot, which

articulates proximally with the medial cuneiform at the tarsometatarsal joint and distally with the metatarsophalangeal joint. 